\title{
LYMPH NODE METASTASIS IN SMALL PERIPHERAL ADENOCARCINOMA OF THE LUNG
}

Tsuneyo Takizawa, $\mathrm{MD}^{\mathrm{a}}$ Masanori Terashima, MD $^{\mathrm{a}}$ Teruaki Koike, MD $^{\mathrm{a}}$

Takehiro Watanabe, $\mathrm{MD}^{\mathrm{a}}$ Yuzo Kurita, $\mathrm{MD}^{\mathrm{b}}$

Akira Yokoyama, $\mathrm{MD}^{\mathrm{b}}$

Keiichi Honma, $\mathrm{MD}^{\mathrm{c}}$
Objective: Our aim in this study is to clarify the clinical and pathologic features of small peripheral adenocarcinoma of the lung with special emphasis on intraoperative identification of lymph node metastasis. $\mathrm{Pa}$ tients and methods: Between 1980 and 1996, 157 patients underwent lobectomy and complete hilar/mediastinal lymphadenectomy for small (1.1 to 2.0 $\mathrm{cm}$ in diameter) peripheral adenocarcinoma of the lung. The intraoperative assessment, the distribution of metastatic lymph nodes, and the association between the tumor's histopathologic characteristics and lymph node metastasis were retrospectively investigated in this study. Results: Postoperative examination revealed lymph node metastasis in $27(17 \%)$ patients. Lymph node metastases were not noticed during the operation in 19 of these 27 patients. Metastases were localized in single lymph nodes in 10 patients; the metastates were distributed over a segmental, a lobar, an interlobar, and a mediastinal lymph node. The prevalence of lymph node metastasis was as follows: Of 92 patients with well-differentiated adenocarcinoma, seven $(8 \%)$ had lymph node metastases; of the 65 patients with other types of tumors, 20 (31\%) had lymph node metastases. Of 120 patients without pleural involvement, 13 (11\%) had lymph node metastases; of the 37 with pleural involvement, $14(38 \%)$ had lymph node metastases. Five-year survivals were estimated at $91 \% \pm 6 \%$ (mean $\pm 95 \%$ confidence interval) for 130 patients with $\mathrm{NO}$ tumor and $30 \% \pm 22 \%$ for 27 patients with $\mathrm{N} 1$ or $\mathrm{N} 2$ tumor. Conclusions: Intraoperative assessment is not reliable for identifying lymph node metastasis. Lobectomy and complete hilar/ mediastinal lymphadenectomy are necessary to determine $\mathrm{N}$ stage rigidly. Histologic degree of differentiation and pleural involvement are significantly associated with lymph node metastasis. (J Thorac Cardiovasc Surg 1998;116:276-80)
$T^{\text {he }}$ he extent of resection has been discussed for small peripheral carcinomas of the lung, ${ }^{1-4}$ because these tumors were regarded as possibly being amenable to lesser resections (segmentectomy and wedge resection) than lobectomy. Lobar and segmental lymph nodes are not removed with lesser

From the Departments of Thoracic Surgery, ${ }^{\mathrm{a}}$ Clinical Oncology, and Pathology ${ }^{\mathrm{c}}$ of Niigata Cancer Hospital, Niigata, Japan.

Supported by grants from the Ministry of Health and Welfare, Japan.

Received for publication August 1, 1997; revisions requested Feb. 2, 1998; revisions received March 11, 1998; accepted for publication April 16, 1998.

Address for reprints: Tsuneyo Takizawa, MD, Department of Thoracic Surgery, Niigata Cancer Center Hospital, 2 Kawagishi-cho, 951 Niigata, Japan.

Copyright (C) 1998 by Mosby, Inc.

$0022-5223 / 98 \$ 5.00+0 \quad \mathbf{1 2 / 1 / 9 1 1 7 6}$ resections, whereas they are removed with lobectomy. Nodal status is assessed with computed tomography ${ }^{5}$ or mediastinoscopy ${ }^{6}$ before the operation. Mediastinal and hilar lymph nodes are explored during the operation by a surgeon. If necessary, a few lymph nodes are sampled and examined pathologically to determine whether they are positive or negative for tumor. However, can all patients with lymph node metastasis be identified before or during the operation? Adenocarcinoma is the most common histologic type of small peripheral lung carcinomas. And adenocarcinoma has considerable potential for lymph node metastasis, even small adenocarcinomas $2 \mathrm{~cm}$ or less in diameter. ${ }^{7,8}$ In this retrospective study, we intended to clarify clinical and pathologic features of small peripheral adenocarcinoma of the lung with special emphasis on lymph node metastasis. 


\section{Patients and methods}

Patients. Between January 1980 and December 1996, 789 patients with clinical stage I peripheral lung cancer underwent lobectomy and complete hilar/mediastinal lymphadenectomy at our hospital. Among them, 157 patients had small-sized adenocarcinomas that ranged from 1.1 to $2.0 \mathrm{~cm}$ in maximum diameter; these patients formed the study group for this retrospective investigation (Table I).

Assessment of nodal status. Mediastinal and hilar lymph nodes were measured through a computed tomographic scan of the thorax before thoracotomy. Lymph nodes were $1 \mathrm{~cm}$ or less in short-axis diameter in each patient, a size that was considered to be within the normal limits. Mediastinoscopy was not used. Lobectomy and complete hilar/mediastinal lymphadenectomy were performed as previously described. ${ }^{9}$ The surgeon reported the intraoperative assessment for lymph node metastasis immediately after the operation. All lymph nodes were arranged by the surgeon according to the mapping of the American Thoracic Society. ${ }^{10}$ Each lymph node was examined pathologically and classified as positive or negative for tumor.

Histopathologic characteristics of the tumors. Tumors were subgrouped into well-differentiated, moderately differentiated, and poorly differentiated adenocarcinoma according to the World Health Organization classification of lung tumors. ${ }^{11}$ Positive pleural involvement was defined as extension of the tumor beyond the elastic layer of the visceral pleura. Pathologic stage was determined according to the new international staging system. ${ }^{12} \mathrm{~T}$ stage was upstaged to $\mathrm{T} 2$ when tumor was exposed on the pleural surface and to T3 when tumor invaded the parietal pleura.

Statistical analysis. The prevalence of lymph node metastasis was evaluated in the category of patient variables (age, sex), tumor size, the degree of differentiation, or the pleural involvement. Univariate analysis of the categoric data was performed using $2 \times 2$ contingency $\chi^{2}$ with Yates' correction for continuity. To further clarify the independent factors association with lymph node metastasis, we performed a multiple logistic regression analysis using the SAS software package (Statistical Analysis Systems, Inc., Cary, N.C.). Postoperative survivals were calculated by the Kaplan-Meier method. The median follow-up period was 1989 days and ranged from 84 to 5511 days. A total of 119 patients were observed for a minimum of 5 postoperative years or until death. Thirty-eight patients were censored according to the Kaplan-Meier method because their follow-up periods were less than 5 years. The statistical difference of survivals was examined by means of the log-rank test.

\section{Results}

Postoperative examination revealed lymph node metastasis in $27(17 \%)$ patients. Table II shows the number of examined nodes, the intraoperative assessment for lymph node metastasis, and the distribution of metastatic lymph nodes. Eleven patients (cases 1 to 11) had N1 metastases. Sixteen patients had N2 metastases (cases 12 to 27). Lymph node
Table I. Characteristics of 157 patients with small peripheral adenocarcinoma of the lung

\begin{tabular}{lcr}
\hline & No. & $\%$ \\
\hline Sex & & \\
Male & 75 & 47 \\
Female & 82 & 53 \\
Age (yr) & & \\
Range & $29-85$ & \\
Median & 64 & \\
Tumor size (cm) & & \\
Range & $1.1-2.0$ & \\
Median & 1.7 & \\
T stage & & \\
T1 & 143 & 1 \\
T2 & 13 & \\
T3 & 1 & 83 \\
N stage & & 7 \\
N0 & 130 & 10 \\
N1 & 11 & \\
N2 & 16 & \\
\hline
\end{tabular}

metastases were noticed during the operation in eight patients (cases 8, 12, 14, 16, 18, 19, 22, and 25), but they were not noticed during the operation in 19 of 27 patients $(70 \%)$. Metastases were localized at single lymph nodes in 10 cases: a segmental node in the one (case 1), a lobar node in the five (cases 2 to 6), a interlobar node in two (cases 9 and 10), a pretracheal node in one (case 19), and a highest mediastinal node in one (case 24). Table III shows the prevalence of lymph node metastasis and the results of univariate analysis for patient variables (age, sex), tumor size, histologic degree of differentiation, or pleural involvement. On univariate analysis, histologic degree of differentiation and pleural involvement were significantly associated with lymph node metastasis. Table IV shows the result of multiple logistic regression analysis. Sex, histologic degree of differentiation, and pleural involvement were significantly associated with lymph node metastasis. The postoperative survival curves are shown in Fig. 1. Five-year survival was estimated at $91 \% \pm$ $6 \%$ (mean $\pm 95 \%$ confidence interval) for 130 patients with N0 tumor. Five-year survival was estimated at $28 \% \pm 22 \%$ for 27 patients with $\mathrm{N} 1$ or N2 tumor. Statistically significant difference was observed between patients with $\mathrm{N} 0$ tumor and those with $\mathrm{N} 1$ or $\mathrm{N} 2$ tumor $(p=0.0000)$.

\section{Discussion}

Can all patients with lymph node metastasis be identified in the preoperative or intraoperative pe- 
Table II. The intraoperative assessment and the distribution of metastatic lymph nodes

\begin{tabular}{|c|c|c|c|c|c|c|c|c|c|c|c|c|c|c|c|}
\hline \multirow[b]{2}{*}{ Case } & \multirow[b]{2}{*}{ No. of nodes } & \multirow[b]{2}{*}{$I A$} & \multicolumn{13}{|c|}{ Lymph node station } \\
\hline & & & 1 & 2 & 3 & 4 & 5 & 6 & 7 & 8 & 9 & 10 & 11 & 12 & 13 \\
\hline 1 & 16 & $\mathrm{~N}$ & & & & & & & & & & & & & 1 \\
\hline 2 & 22 & $\mathrm{~N}$ & & & & & & & & & & & & 1 & \\
\hline 3 & 13 & $\mathrm{~N}$ & & & & & & & & & & & & 1 & \\
\hline 4 & 17 & $\mathrm{~N}$ & & & & & & & & & & & & 1 & \\
\hline 5 & 12 & $\mathrm{~N}$ & & & & & & & & & & & & 1 & \\
\hline 6 & 20 & $\mathrm{~N}$ & & & & & & & & & & & & 1 & \\
\hline 7 & 27 & $\mathrm{~N}$ & & & & & & & & & & & & 1 & 2 \\
\hline 8 & 30 & $\mathrm{P}$ & & & & & & & & & & & & 2 & 1 \\
\hline 9 & 11 & $\mathrm{~N}$ & & & & & & & & & & & 1 & & \\
\hline 10 & 13 & $\mathrm{~N}$ & & & & & & & & & & & 1 & & \\
\hline 11 & 11 & $\mathrm{~N}$ & & & & & & & & & & & 1 & 1 & \\
\hline 12 & 19 & $\mathrm{P}$ & & & & & & & 1 & & & & & 1 & \\
\hline 13 & 39 & $\mathrm{~N}$ & & & & & & & 2 & & & & 1 & 2 & \\
\hline 14 & 22 & $\mathrm{P}$ & & & & & & 1 & & & & & 1 & & \\
\hline 15 & 14 & $\mathrm{~N}$ & & & & & & 1 & & & & 1 & 2 & 1 & \\
\hline 16 & 12 & $\mathrm{P}$ & & & & & 2 & & 2 & & & & & & 1 \\
\hline 17 & 26 & $\mathrm{~N}$ & & & & & 2 & 1 & & & & & & & 1 \\
\hline 18 & 19 & $\mathrm{P}$ & & & & 1 & & 1 & & & & & & 2 & \\
\hline 19 & 24 & $\mathrm{P}$ & & & 1 & & & & & & & & & & \\
\hline 20 & 9 & $\mathrm{~N}$ & & & 1 & 1 & & & & & & & 1 & 1 & 1 \\
\hline 21 & 24 & $\mathrm{~N}$ & & & 2 & & & & & & & & 1 & & \\
\hline 22 & 56 & $\mathrm{P}$ & & & 5 & & & & 2 & & & & & & \\
\hline 23 & 25 & $\mathrm{~N}$ & & 1 & 1 & & & & & & & & 1 & & \\
\hline 24 & 15 & $\mathrm{~N}$ & 1 & & & & & & & & & & & & \\
\hline 25 & 25 & $\mathrm{P}$ & 2 & 4 & & & & & 4 & & & & & & 1 \\
\hline 26 & 13 & $\mathrm{~N}$ & 2 & 1 & 1 & & & & & & & & 1 & 1 & \\
\hline 27 & 26 & $\mathrm{~N}$ & 2 & 1 & 2 & 4 & & & & & & & 1 & & \\
\hline
\end{tabular}

No. of nodes, Number of nodes examined; $I A$, intraoperative assessment; $N$, negative for tumor; $P$, positive for tumor. Lymph node stations are numbered according to the American Thoracic Society. A figure in the column of lymph node stations is the number of metastatic lymph nodes.

Table III. Prevalence of lymph node metastasis and results of univariate analyses

\begin{tabular}{lccc}
\hline \multicolumn{1}{c}{ Factors } & Prevalence & $\%$ & $p$ Value \\
\hline Age (yr) & & & \\
29-63 & $14 / 77$ & 18 & 0.912 \\
$\quad 64-85$ & $13 / 80$ & 16 & \\
Sex & & & \\
$\quad$ Male & $11 / 75$ & 15 & 0.553 \\
$\quad$ Female & $16 / 82$ & 20 & \\
Tumor size (cm) & & & \\
$\quad$ 1.1-1.5 & $6 / 43$ & 14 & 0.6702 \\
$\quad$ 1.6-2.0 & $21 / 114$ & 18 & \\
Degree of differentiation & & & \\
$\quad$ Well differentiated & $7 / 92$ & 8 & 0.0004 \\
$\quad$ Other & $20 / 65$ & 31 & \\
Pleural involvement & & & \\
$\quad$ Negative & $13 / 120$ & 11 & 0.0004 \\
$\quad$ Positive & $14 / 37$ & 38 & \\
\hline
\end{tabular}

riod? In this study, computed tomographic scan falsely predicted negative nodal involvement in $17 \%$ of patients with small peripheral adenocarcinoma of the lung. The surgeons could not detect metastases in $70 \%$ of patients with nodal involvement. Metastases were localized at single lymph nodes in $37 \%$ of patients with nodal involvement; these single nodal metastases were distributed over a segmental, a lobar, a hilar, and a mediastinal lymph node. These observations suggest that it is almost impossible to identify all lymph node metastasis before or during the operation. Lobar and segmental lymph nodes, which are removed with lobectomy, remain unremoved with lesser resections. Microscopic metastases possibly exist in these lymph nodes if lymph node metastasis is not identified before or during the operation. This may be one reason that the incidence of local recurrence was significantly higher in lesser resections (segmentectomy and wedge resection) than in lobectomy. ${ }^{2-4}$

A few authors report that several histopathologic characteristics of small adenocarcinoma are associated with postoperative prognosis. ${ }^{7,}{ }^{13,14}$ Both histologic degree of differentiation and pleural involvement were significantly associated with lymph node metastasis in this study. Preoperative or intraoper- 


\section{$\%$ Surviving}

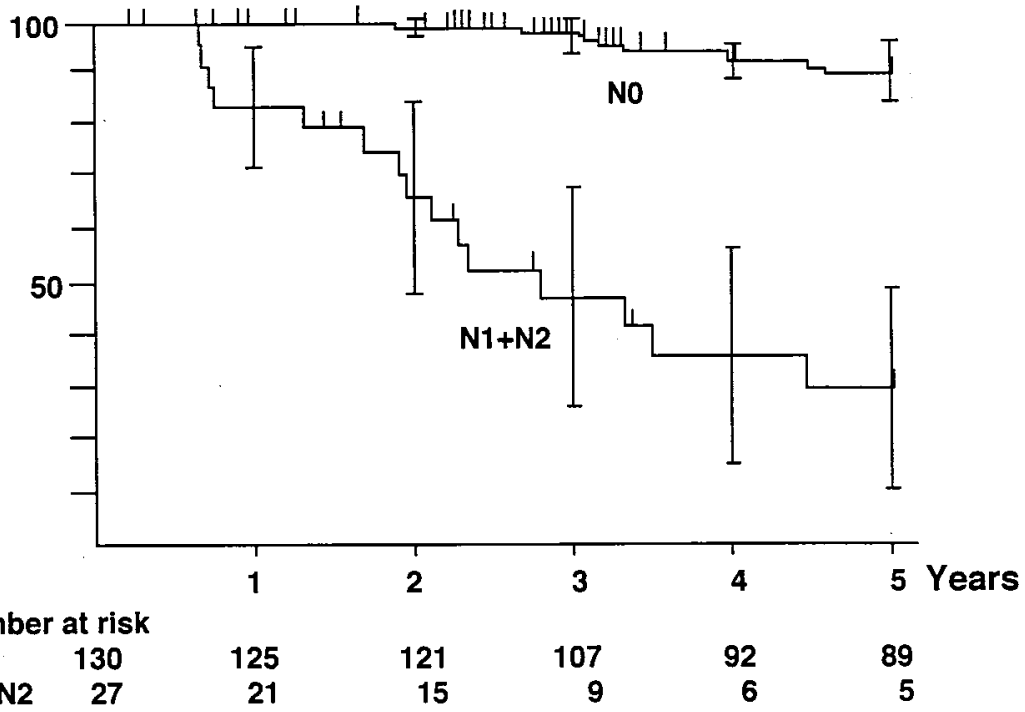

Fig. 1. Postoperative survival curves. NO, Patients with N0 tumor; $N 1+N 2$, patients with N1 or N2 tumor. Bars indicate $95 \%$ confidence intervals.

Table IV. Results of logistic analysis for coexistence of lymph node metastasis

\begin{tabular}{lcccc}
\hline & & & \multicolumn{2}{c}{ 95\% Confidence limits } \\
\cline { 4 - 5 } \multicolumn{1}{c}{ Variables } & p Value & Odds ratio & Lower & Upper \\
\hline Age (yr) & 0.7484 & 1.00 & 0.95 & 1.06 \\
Sex (male, 0; female, 1) & 0.0362 & 2.95 & 1.07 & 8.10 \\
Tumor size (cm) & 0.2759 & 1.08 & 0.93 & 1.25 \\
Degree of differentiation (well differentiated, 0; other, 1) & 0.0003 & 7.06 & 2.47 & 20.20 \\
Pleural involvement (negative, 0; positive, 1) & 0.0021 & 4.57 & 1.73 & 12.02 \\
\hline
\end{tabular}

ative identification of these histopathologic characteristics will help surgeons to assess lymph node metastasis and to decide the extent of resection or lymphadenectomy for patients in the poor-risk category. Postoperative 5-year survival is estimated to be high $(91 \% \pm 6 \%)$ for patients with N0 tumor, although it is estimated to be low $(30 \% \pm 22 \%)$ for patients with $\mathrm{N} 1$ or $\mathrm{N} 2$ tumor. This observation indicates that $\mathrm{N}$ stage is rigidly determined in our patients who underwent lobectomy and complete hilar/mediastinal lymphadenectomy.

In conclusion, intraoperative assessment is not reliable for identifying lymph node metastasis in small peripheral adenocarcinoma of the lung. Lobectomy and complete hilar/mediastinal lymphadenectomy are necessary to determine $\mathrm{N}$ stage rigidly. Histologic degree of differentiation and pleural involvement are associated with lymph node metastasis.

\section{REFERENCES}

1. Pearson FAG. Current status of surgical resection for lung cancer. Chest 1994;106:337s-9s.

2. Martini N, Bains MS, Burt ME, et al. Incidence of local recurrence and second primary tumors in resected stage I lung cancer. J Thorac Cardiovasc Surg 1995;109:120-9.

3. Warren WH, Faber LP. Segmentectomy versus lobectomy in patients with stage I pulmonary carcinoma: five-year survival and patterns of intrathoracic recurrence. J Thorac Cardiovasc Surg 1994;107:1087-94.

4. Lung Cancer Study Group. Randomized trial of lobectomy versus limited resection for T1N0 non-small cell lung cancer. Ann Thorac Surg 1995;60:615-23.

5. Lewis JW Jr, Perlberg JL, Beute GH, et al. Can computed tomography of the chest stage lung cancer? Yes and no. Ann Thorac Surg 1990;49:591-6.

6. Schil PE, Hee RH, Schoofs EL. The value of mediastinoscopy in preoperative staging of bronchogenic carcinoma. J Thorac Cardiovasc Surg 1989;97:240-4.

7. Takise A, Kodama T, Shimosato Y, Watanabe S, Suemasu K. Histopathological prognostic factors in adenocarcinomas of the peripheral lung less than $2 \mathrm{~cm}$ in diameter. Cancer 1988;61:2083-8.

8. Asamura H, Nakamura H, Kondo H, Tsuchiya R, Naruke T. 
Lymph node involvement, recurrence, and prognosis in resected peripheral, non-small-cell lung carcinomas: Are these carcinomas candidates for video-assisted lobectomy? J Thorac Cardiovasc Surg 1996;111:1125-34.

9. Takizawa T, Terashima M, Koike T, Akamatsu H, Kurita Y, Yokoyama A. Mediastinal lymph node metastasis in patients with clinical stage I peripheral non-small-cell lung cancer. J Thorac Cardiovasc Surg 1997;113:248-52.

10. Tisi GM, Friedman PH, Peters RM, et al. American Thoracic Society: Clinical staging of primary lung cancer. Am Rev Respir Dis 1983;127:659-64.
11. World Health Organization. Histological typing of lung tumors. 2nd ed. Geneva: World Health Organization; 1981.

12. Mountain CF. A new international staging system for lung cancer. Chest 1986;89(suppl 4):225-33.

13. Noguchi M, Morikawa A, Kawasaki M, et al. Small adenocarcinoma of the lung. Cancer 1995;75:2844-52.

14. Ichinose $\mathrm{Y}$, Yano $\mathrm{T}$, Asoh H, Yokoyama H, Yoshino I, Katsuda Y. Prognostic factors obtained by a pathologic examination in completely resected non-small-cell lung cancer: an analysis in each pathologic stage. J Thorac Cardiovasc Surg 1995;110:601-5.

\section{Availability of Journal back issues}

As a service to our subscribers, copies of back issues of The Journal of Thoracic and Cardiovascular Surgery for the preceding 5 years are maintained and are available for purchase from Mosby at a cost of $\$ 16.00$ per issue until inventory is depleted. The following quantity discounts are available: $25 \%$ off on quantities of 12 to 23 , and one third off on quantities of 24 or more. Please write to Mosby, Inc., Subscription Services, 11830 Westline Industrial Drive, St. Louis, MO 63146-3318, or call 800-453-4351 or 314-453-4351 for information on availability of particular issues. If unavailable from the publisher, photocopies of complete issues may be purchased from UMI, 300 N. Zeeb Rd., Ann Arbor, MI 48106, 313-761-4700. 